\title{
OCT3 and SOX2 promote the transformation of Barrett's esophagus to adenocarcinoma by regulating the formation of tumor stem cells
}

\author{
XINGWEI WANG ${ }^{1}$, SHIMING YANG ${ }^{1}$, XIAOYAN ZHAO ${ }^{1}$, HONG GUO $^{1}$, XIANLONG LING $^{1}$, \\ LEI WANG $^{1}$, CHAOQIANG FAN ${ }^{1}$, JING YU ${ }^{1}$ and SHIWEN ZHOU ${ }^{2}$ \\ ${ }^{1}$ Department of Gastroenterology and ${ }^{2}$ National Base for Drug Clinical Trial, The Second Affiliated Hospital, \\ Third Military Medical University, Chongqing 400037, P.R. China
}

Received October 30, 2013; Accepted December 20, 2013

DOI: $10.3892 /$ or.2014.3003

\begin{abstract}
Barrett's esophagus (BE) is a type of precancerosis and a key risk factor for esophagus adenocarcinoma (EAC). Tumor stem cells may be the source for BE transforming to EAC. Octamer transcription factor-3/4 (OCT3/4) and SOX2 are the main transcriptional controlling factors and markers of tumor stem cells. In the present study, we observed that the expressions of OCT3/4, SOX2, TCL1 and AKT1 in BE were elevated compared to normal esophagus but were decreased compared to EAC. Moreover, we isolated a few stem-like cells in OE33 cells which showed similar biological behavior to tumor stem cells. Notably, we found that downregulation of OCT3/4 expression by siRNA inhibited the ability of clone formation and invasion of OE33 cells, and decreased the formation of side population cells and slow cycle cells. Therefore, we concluded that OCT3/4 and SOX2 play a critical role in the transformation of BE to EAC by regulating the formation of tumor stem cells and the TCL1/AKT1 pathway.
\end{abstract}

\section{Introduction}

Barrett's esophagus (BE) is the physical phenomenon that the stratified squamous epithelia of the lower esophagus are substituted by metaplastic simple columnar epithelia. BE is a type of precancerosis of esophagus adenocarcinoma (EAC). The incidence of EAC has markedly increased, especially in Western industrialized countries (1). For BE patients, the risk of developing EAC has increased 30-125-fold compared to individuals not suffering from BE. Therefore, BE is considered the key risk factor for EAC (2). However, the factors

Correspondence to: Professor Shiwen Zhou, National Base for Drug Clinical Trial, The Second Affiliated Hospital, Third Military Medical University, 183 Xinqiao Main Street, Shapingba, Chongqing 400037, P.R. China

E-mail: zhoushiwen2013@163.com

Key words: Barrett's esophagus, esophagus adenocarcinoma, tumor stem cell, octamer transcription factor-3, SOX-2 transcription factor that play a critical role in the transformation of $\mathrm{BE}$ to $\mathrm{EAC}$ remain unclear. In recent years, tumor stem cells have been regarded as the source of tumor growth, metastasis and recurrence due to their potential of self-renewal and differentiation. Tumor stem cells are known to exist in different tumors from several types of tissues and organs. Tumor cells, especially poorly differentiated tumor cells exhibit similar phenotypes and biological characteristics as stem cells. For example, they both have the ability of self-renewal and differentiation $(3,4)$. Therefore, it may be assumed that tumor stem cells are the source of the transformation of BE to EAC. Octamer transcription factor-3 (OCT3) and SOX2 are the transcription factors necessary to maintain cell totipotency; they play critical roles in the regulation of embryo development and are involved in self-renewal of embryonic stem cells or primordial germ cells. OCT 3 and SOX 2 combine to form an OCT3/SOX 2 complex, bind to target genes in a sequence-specific manner and play a vital role in the signal regulation network of stem cells $(5,6)$. Our previous studies demonstrated that according to gene chip analysis, the expression of OCT3, SOX2 and their downstream candidate gene TCL1/AKT1 were upregulated in BE tissue (7). Therefore, we assumed that during the progression of the transformation of BE to EAC, OCT3 and SOX2 in the metaplastic simple columnar epithelium were activated and combined to form the OCT3/SOX2 complex, they switched on the TCL1/AKT1 signal pathway, and then promoted the transformation of epithelium cells to stem cells with the ability of continued proliferation and differentiation. In the present study, firstly, the expressions of OCT3, SOX2, TCL1 and AKT1 in BE and EAC tissue, respectively, was observed, and then the stem-like cells (SP and slow cycle cells) were isolated from EAC cell lines (OE33) and their biological characteristics were observed. Furthermore, the present study demonstrated the impact of OCT3 siRNA on the expression of SOX2, TCL1 and AKT1, and described the biological characteristics of stem-like cells.

\section{Materials and methods}

Clinical specimens. The biopsy specimens of BE from 58 patients were obtained by endoscopy and the specimens 
of EAC were from surgical ablation performed in 42 patients at the Second Affiliated Hospital of the Third Military Medical University. At the same time, 30 normal esophagus tissue specimens were obtained through endoscopy. Routine histopathologic analysis was performed by experienced gastrointestinal pathologists to confirm the diagnosis. The specimens were cut into sections, snap-frozen in liquid nitrogen and stored at $-80^{\circ} \mathrm{C}$ for future RNA extraction. The study was approved by the Institutional Human Ethics Committee.

Cell lines and antibodies. Human poorly differentiated EAC cell line OE33 was purchased from the European Collection of Cell Cultures (ECACC; Salisbury, UK), and maintained in Dulbecco's modified Eagle's medium (DMEM) supplemented with $10 \%$ fetal bovine serum (FBS) at $37^{\circ} \mathrm{C}$ in a humidified atmosphere of $5 \% \mathrm{CO}_{2}$ and $95 \%$ air. The cell line was established from a poorly differentiated lower esophageal adenocarcinoma of a female Caucasian patient who had Barrett's metaplasia (8). Anti-human OCT3, anti-human SOX2, anti-human TCL1 and anti-human AKT1 antibodies were purchased from Santa Cruz Biotechnology, Inc. (Santa Cruz, CA, USA). Anti- $\beta$-actin, horseradish peroxidase (HRP)-coupled antibodies were from BioDev-Tech Co. (Beijing, China).

Immunohistochemical detection. Protein expression was detected by immunohistochemistry using the LSAB kit (Dako, Denmark) according to the manufacturer's instructions. The $5 \mu \mathrm{m}$ sections made from BE, EAC or normal esophagus tissue were deparaffinized in xylene and microwaved in $10 \mathrm{mM}$ citrate buffer ( $\mathrm{pH}$ 6.0) to unmask the epitopes. The OCT3, SOX2, TCL1 and AKT1 antibodies (Santa Cruz Biotechnology, Inc.) were diluted 1:100, and the HRP-labeled secondary antibody was diluted 1:1,000. The sections were incubated with the target antibodies overnight at $4^{\circ} \mathrm{C}$. After washing three times, the sections were incubated with HRP-labeled antibodies for $30 \mathrm{~min}$ at room temperature. Thereafter, the sections were stained for $5 \mathrm{~min}$ with diaminobenzidine tetrahydrochloride (DAB), counterstained with hematoxylin, dehydrated and mounted onto Diatex. Positive cells showed brownish yellow nuclei or cytoplasm. Ten visual fields under the microscope were selected and were analyzed with Image-Pro Plus version 6.2 software (Media Cybernetics) using a special function called 'measurement of integrated absorbance', which evaluates both the area and the intensity of positive staining. Using this function, integrated absorbance of all positive staining of the proteins in each image was measured and its proportion of the total area of each image was calculated. The density of $\beta$-actin was used as positive control and buffer at the same concentration was used as negative control.

Protein extraction and western blot analysis. Total cellular protein was extracted on ice for $30 \mathrm{~min}$ in lysis buffer [50 mmol/1 Tris- $\mathrm{HCl}, 150 \mathrm{mmol} / \mathrm{l} \mathrm{NaCl}, 5 \mathrm{mmol} / 1$ EDTA, $1 \mathrm{mmol} / 1$ phenylmethylsulfonyl fluoride (PMSF) and protease inhibitors (PIs)]. For western blot analyses, $50 \mu \mathrm{g}$ protein from each sample was denatured in $2 \mathrm{X}$ loading buffer at $100^{\circ} \mathrm{C}$ for $5 \mathrm{~min}$, separated by sodium dodecyl sulfate-polyacrylamide gel electrophoresis (SDS-PAGE) gel and then transferred onto a nitrocellulose membrane. The membranes were then incubated in $5 \%$ skim milk at room temperature for $2 \mathrm{~h}$, followed by addition of the first antibody $(1: 1,000)$ and incubation at $4{ }^{\circ} \mathrm{C}$ overnight. The following day, the membranes were washed three times with phosphate-buffered saline (PBS), followed by incubation with the secondary antibody at room temperature for $2 \mathrm{~h}$. The protein bands were finally visualized on X-ray film using ECL. The images were subjected to grayscale analysis using BandScan software.

Primer pairs and hydrolysis probe for real-time PCR. The primers and hydrolysis probes for OCT3, COT4, SOX2 and GAPDH were designed by Universal Probe Library Assay Design Center (Roche, Mannheim, Germany) (Table I). The primers were synthesized by TIB MolBiol (USA) and the hydrolysis probe was purchased from Roche.

RNA isolation, RT-PCR and real-time RT-PCR analysis. RNA was extracted from tissue samples using the High Pure RNA Tissue kit (Roche) and from cell lines using the RNeasy Mini kit (Qiagen, Hilden, Germany) according to the manufacturer's recommendations. The cDNA preparation from total RNA was performed with $500 \mathrm{ng}$ RNA (20 $\mu$ l total volume) using the Script cDNA Synthesis kit (Bio-Rad, Munich, Germany). Quantitative analysis of target gene transcripts was performed by real-time RT-PCR using the QuantiTect SYBR-Green PCR kit (Qiagen). For the amplification, an initial denaturation at $95^{\circ} \mathrm{C}$ for $15 \mathrm{~min}$, followed by $15 \mathrm{sec}$ at $94^{\circ} \mathrm{C}, 30 \mathrm{sec}$ at $55^{\circ} \mathrm{C}$ and $30 \mathrm{sec}$ at $72^{\circ} \mathrm{C}$ for 35 cycles was used. Samples were run on a LightCycler ${ }^{\circledR} 480$ Real-Time PCR system (Roche). The relative expressions were calculated by normalization to GAPDH gene expression.

Isolation of side population (SP) and main population (MP) cells from the OE33 cell line using Hoechst 33342 dye. The cells were suspended in pre-warmed RPMI-1640 containing $2 \%$ FBS and $2 \mathrm{mM}$ HEPES (HBSS) at $1 \times 10^{6}$ cells $/ \mathrm{ml}$ at $37^{\circ} \mathrm{C}$ for $10 \mathrm{~min}$, and incubated at $37^{\circ} \mathrm{C}$ for an additional $90 \mathrm{~min}$ in a shaking bath with $5 \mu \mathrm{g} / \mathrm{ml}(8.1 \mu \mathrm{M})$ Hoechst 33342 dye. Control cells were incubated with $50 \mu \mathrm{M}$ verapamil (Sigma, St. Louis, MO, USA) for $15 \mathrm{~min}$ at $37^{\circ} \mathrm{C}$ before Hoechst dye addition. After centrifugation at $1,300 \mathrm{rpm}$ at $4^{\circ} \mathrm{C}$ for $5 \mathrm{~min}$, cells were washed and resuspended in cold HBSS containing $20 \mu \mathrm{g} / \mathrm{l}$ PI and then placed immediately on ice. The SP/MP cells were gated separately and analyzed using an LSR II flow cytometer (BD Biosciences, San Jose, CA, USA). The blue light signal was collected by a $450 / 20$ band pass filter, and the red light signal was collected by a $675 \mathrm{~nm}$ pass filter. PI-positive dead cells were removed. Among the PI-negative cells, Hoechst 33342-negative or weakly-positive cells were considered the SP subgroup, and Hoechst 33342-positive cells were considered the MP group.

Isolation of slow cycle cells and rapid cycle cells from the OE33 cell line by Dil dye. Cells were incubated at $37^{\circ} \mathrm{C}$ for $5 \mathrm{~min}$ with $5 \mu \mathrm{l} / \mathrm{ml}$ Dil dye. Then, the cells were washed three times with RPMI-1640 to remove the Dil dye. After culturing for 5-6 weeks, only very few cells were illuminated under the inverted fluorescence microscope. Next, the cells were isolated using the LSR II flow cytometer and the red light signal was collected by an 585/40 nm filter. Slow cycle cells were Dil-positive and rapid cycle cells were Dil-negative. 
Table I. The primers of OCT3 and SOX2.

\begin{tabular}{llccc}
\hline Gene & \multicolumn{1}{c}{ Primer sequences } & Location & Length (bp) & No. \\
\hline OCT3/4 & F: 5'-AGCAAAACCCGGAGGAGT-3' & $443-460$ & 114 & $\# 35$ \\
NM_002701 & R: 5'-CCACATCGGCCTGTGTATATC-3' & $536-556$ & & 4687680001 \\
SOX2 & F: 5'-TTGCTGCCTCTTTAAGACTAGGA-3' & $76-98$ & 75 & $\# 35$ \\
NM_003106 & R: 5'-CTGGGGCTCAAACTTCTCTC-3' & $131-150$ & & 4687680001 \\
GAPDH & F: 5'-AGCCACATCGCTCAGACA-3' & $83-101$ & 66 & $\# 60$ \\
& R: 5'-GCCCAATACGACCAAATCC-3' & $130-148$ & & 4688589001 \\
OCT3/4 & F: 5'-TCCCTTCGCAAGCCCTCAT-3' & $-2-17$ & 408 & \\
Specific & R: 5'-TGACGGTGCAGGGCTCCGGGGAGGCCCCATC-3' & $376-406$ & & \\
\hline
\end{tabular}

OCT3, octamer transcription factor-3; F, forward; R, reverse.

Colony forming efficiency assay. The isolated cells were plated at 300 cells/well in a six-well tissue culture plate and grown for 14 days until macroscopic cell clones were demonstrated. The cells were then fixed with $95 \%$ cold methanol for $15 \mathrm{~min}$ at $4{ }^{\circ} \mathrm{C}$ and stained with $0.5 \%$ methylene blue solution for $2 \mathrm{~min}$ in order to count the number of colonies by microscopy. Colony forming efficiency was calculated as the percentage of single cells that generated colonies at day 14. Cell clone formation rate $=($ number of clones $/ 300) \times 100 \%$.

In vitro invasion assay. In the Transwell chamber assay (Chemicon, USA), $50 \mu 1$ cell suspension $\left(1 \times 10^{5}\right.$ cells $\left./ \mathrm{ml}\right)$ was added into the chamber's upper insert. After $24 \mathrm{~h}$ in cell culture, the internal cell layer was scraped from the chamber, fixated with $10 \%$ formalin, Giemsa stained and membranepenetrating cells were counted.

siRNA construction and cell transfection. Three OCT3, SOX2 siRNA sequences purchased from Qiagen (USA) were sequenced and blast compared. The results confirmed consistency with human OCT3 and SOX 2 cDNAs as registered in GenBank. These sequences were mixed with Oligofectamine (Invitrogen, USA) to obtain a concentration of $100 \mathrm{nM}$, and then transfected into OE33 cells $\left(1 \times 10^{5}\right.$ cells $\left./ \mathrm{ml}\right)$. At the same time, the blank control group (ConB), void vector group (ConA) and negative transfection group (ConN) were placed. PBS was added to the ConB group. Void vectors of the same concentration were added to the Con A group. Negative sequences to the target genes were added to the ConN group.

Statistical analysis. Data are summarized as means \pm SD from three or more independent experiments. Statistical analysis was performed by using two-tailed Student's t-test for paired data. $\mathrm{p}<0.05$ was considered to indicate a statistically significant difference.

\section{Results}

The expressions of OCT3, SOX2, TCL1 and AKT1 increase in BE tissue compared to normal esophagus tissue, respectively, but decrease compared to EAC tissue. Immunohistochemical detection showed positive staining of OCT3, SOX2, TCL1 and
AKT1 proteins, demonstrated by yellow or brown color and mainly located in cell nuclei (Fig. 1). Only traces of the expression of the proteins mentioned above were detected in normal esophagus tissue, but expression was elevated in BE tissue and EAC tissue. Analysis of areas of positive expression using the Image-Pro Plus system indicated that the absorbance values, and total absorbance values of the four proteins mentioned above were increased in $\mathrm{BE}$ tissue compared to normal tissue $(\mathrm{p}<0.01)$ but decreased compared to EAC tissue $(\mathrm{p}<0.05)$, respectively (Table II).

SP cells and slow cycle cells are isolated from the EC33 cell line. Most of the EC33 cells exhibited fluorescence after dyeing with Hoechst 33342, but there were still a few cells that did not show any fluorescence, and these were SP cells, and the others were MP cells. SP cells were smaller than MP cells observed under fluorescence microscope. As analyzed by FCM, the proportion of SP cells among all EC33 cells was $1.2 \pm 0.18 \%$ located in the bottom left quadrant. After dyeing with Dil and culturing for 5-6 weeks, most EC33 cells did not exhibit any red fluorescence. Only a few cells exhibited red fluorescence, and these were slow cycle cells, and others were quick cycle cells. Slow cycle cells were smaller than quick cycle cells. The proportion of slow cycle cells among all cells was $\sim 1.4 \pm 0.26 \%$, analyzed by FCM (Fig. 2).

The ability of clone formation and the invasion of SP cells and slow cycle cells are strengthened. The plate clone formation test showed the number of clones formed by SP cells was $186 \pm 24$, and the rate of clone formation was $58.65 \pm 6.32 \%$. The number of clones formed by MP cells was $68 \pm 18$, and the rate of clone formation was $22.6 \pm 2.44 \%$. There was a statistically significant difference between SP and MP cells $(\mathrm{t}=3.486, \mathrm{p}<0.01)$. The number of clones formed by slow cycle cells $(192 \pm 46)$ and the rate of clone formation $(61.82 \pm 7.63 \%)$ were statistically significantly higher compared to the quick cycle cells $(58 \pm 11,17.2 \pm 1.2 \%)(\mathrm{t}=5.326, \mathrm{p}<0.01)($ Fig. $3 \mathrm{~A})$. The Transwell chamber assay showed the Transwell rate of SP cells was $38.25 \pm 5.68 \%$, compared to a Transwell rate of MP cells of $2.36 \pm 0.23 \%$. There was a statistically significant difference between SP and MP cells $(\mathrm{t}=3.586, \mathrm{p}<0.01)$. The Transwell rate of slow cycle cells $(42.34 \pm 6.86 \%)$ was statistically significantly 
Table II. The expression of OCT3, SOX2, TCL1 and AKT1 detected by immunohistochemistry (mean \pm SD).

\begin{tabular}{|c|c|c|c|c|c|c|c|}
\hline \multirow[b]{2}{*}{ Groups } & \multirow[b]{2}{*}{$\mathrm{n}$} & \multicolumn{3}{|c|}{ OCT3/4 } & \multicolumn{3}{|c|}{$\mathrm{SOX} 2$} \\
\hline & & Area $\left(\mu \mathrm{m}^{2}\right)$ & Density & Absorbance & Area $\left(\mu \mathrm{m}^{2}\right)$ & Density & Absorbance \\
\hline EAC & 42 & $4267 \pm 446$ & $0.33 \pm 0.06^{\mathrm{a}}$ & $1515 \pm 417^{\mathrm{a}}$ & $5386 \pm 568$ & $0.42 \pm 0.07^{\mathrm{a}}$ & $2268 \pm 526^{a}$ \\
\hline $\mathrm{BE}$ & 58 & $4063 \pm 434$ & $0.20 \pm 0.03^{b}$ & $809 \pm 129^{b}$ & $5568 \pm 464$ & $0.22 \pm 0.03^{b}$ & $1085 \pm 146^{\mathrm{b}}$ \\
\hline \multirow[t]{2}{*}{ Normal } & 30 & $4139 \pm 188$ & $0.08 \pm 0.03$ & $326 \pm 48$ & $5033 \pm 126$ & $0.06 \pm 0.02$ & $332 \pm 38$ \\
\hline & & \multicolumn{3}{|c|}{ TCL1 } & \multicolumn{3}{|c|}{ AKT1 } \\
\hline Groups & $\mathrm{n}$ & Area $\left(\mu \mathrm{m}^{2}\right)$ & Density & Absorbance & Area $\left(\mu \mathrm{m}^{2}\right)$ & Density & Absorbance \\
\hline EAC & 42 & $4487 \pm 446$ & $0.37 \pm 0.05^{\mathrm{a}}$ & $1678 \pm 438^{\mathrm{a}}$ & $4267 \pm 446$ & $0.33 \pm 0.06^{\mathrm{a}}$ & $1515 \pm 417^{\mathrm{a}}$ \\
\hline $\mathrm{BE}$ & 58 & $4218 \pm 334$ & $0.21 \pm 0.03^{\mathrm{ab}}$ & $842 \pm 136^{\mathrm{ab}}$ & $4063 \pm 334$ & $0.20 \pm 0.03^{\mathrm{ab}}$ & $829 \pm 129^{a b}$ \\
\hline Normal & 30 & $4213 \pm 188$ & $0.06 \pm 0.03$ & $232 \pm 36$ & $3987 \pm 198$ & $0.04 \pm 0.03$ & $152 \pm 16$ \\
\hline
\end{tabular}

${ }^{\mathrm{a}} \mathrm{p}<0.05$ compared to normal group; ${ }^{\mathrm{b}} \mathrm{p}<0.05$ compared to EAC group. OCT3, octamer transcription factor-3; EAC, esophagus adenocarcinoma; BE, Barrett's esophagus.

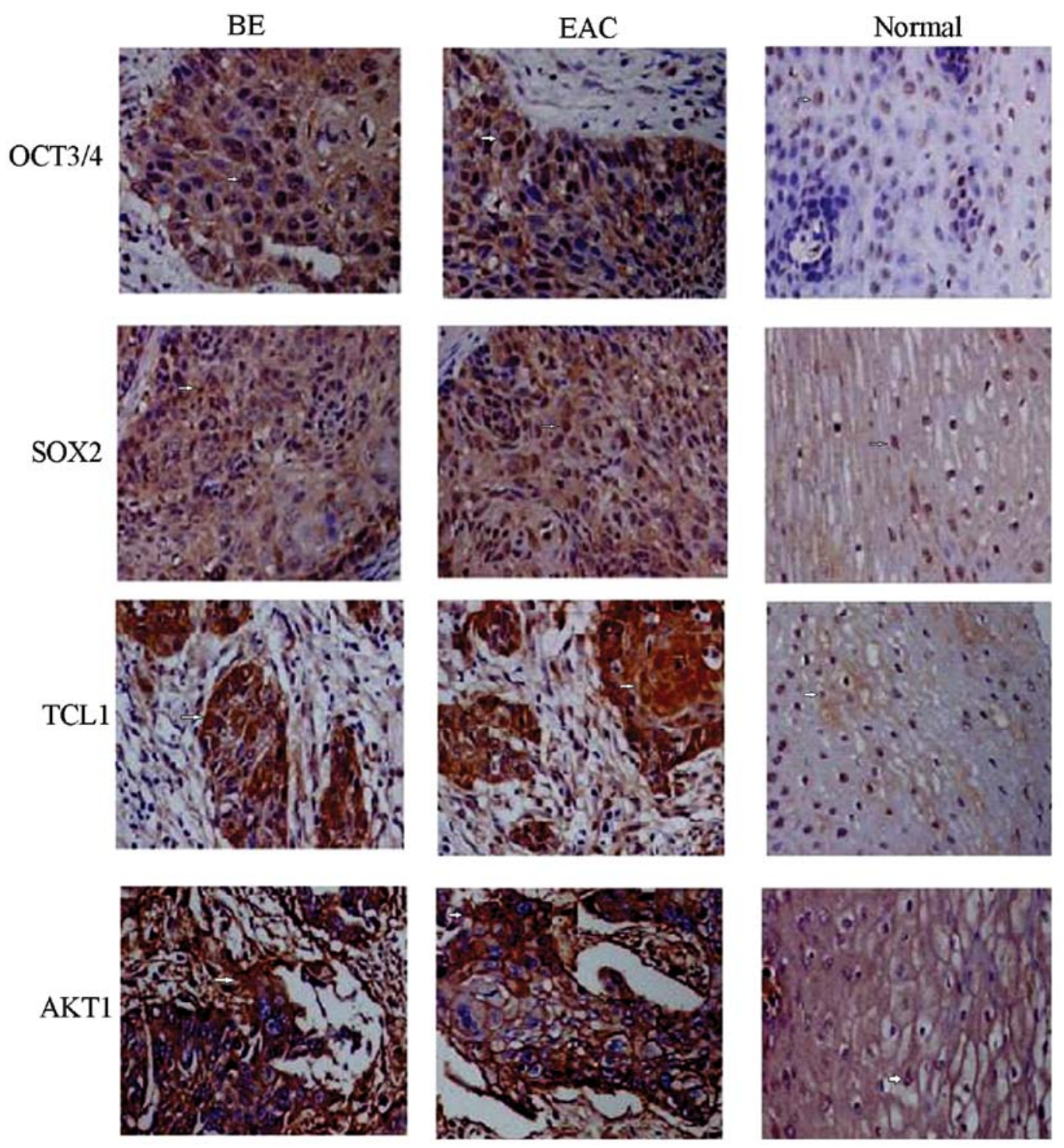

Figure 1. The positive staining of OCT3, SOX2, TCL1 and AKT1 proteins are yellow or brown and are mainly located in the cell nuclei. OCT3, octamer transcription factor-3. 

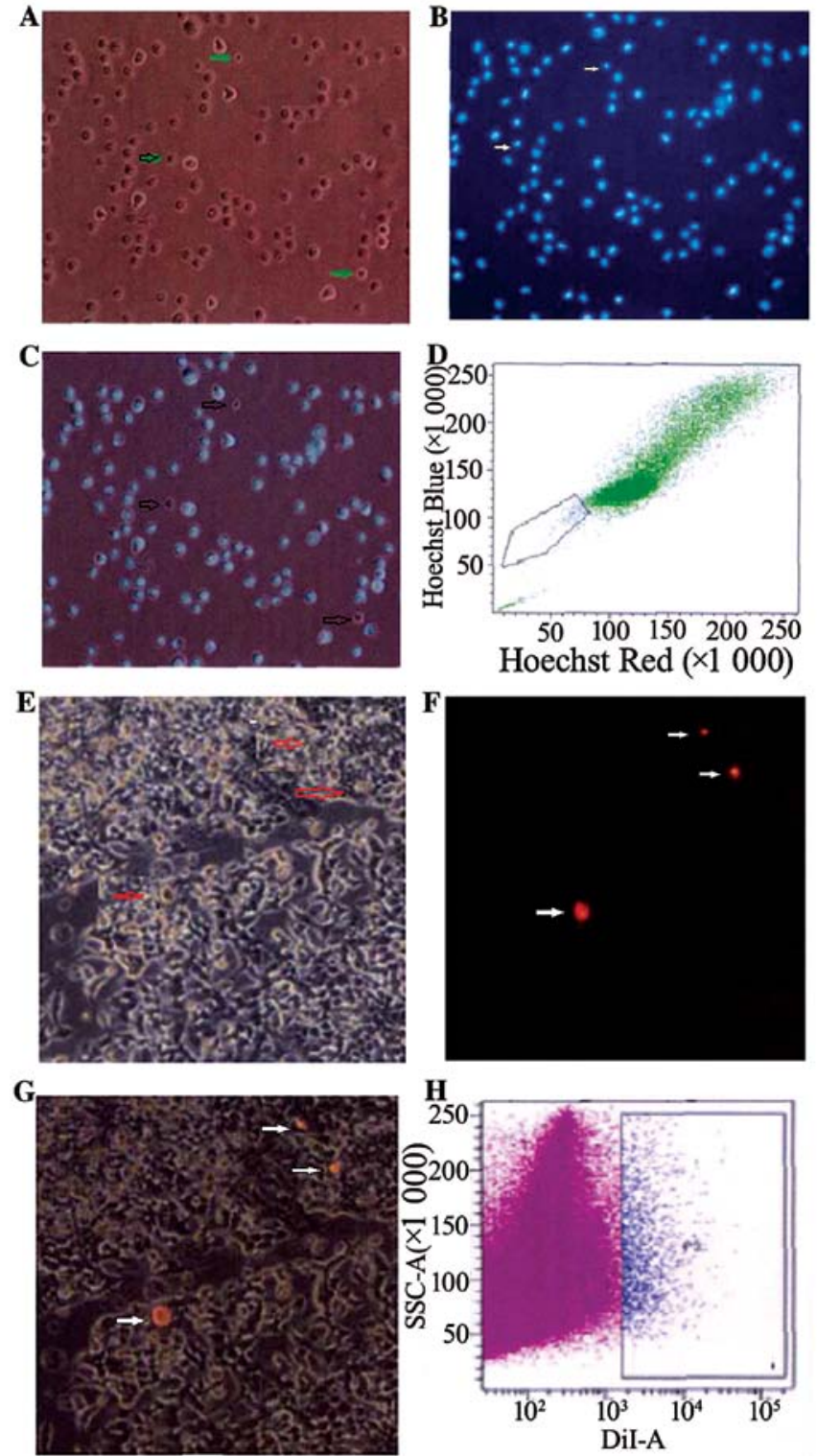

Figure 2. SP cells isolated from an EC33 cell line. (A) SP cells are smaller than MP cells when observed under a light microscope, the arrows point to an SP cell. (B) SP cells do not demonstrate fluorescence under a fluorescence microscope. (C) Cells observed under a light microscope mixed together with a fluorescence microscope, the arrows point to an SP cell. (D) FCM analysis indicates an SP cell proportion of $1.2 \%$. (E) Cells observed under a light microscope, the arrows point to an SP cell. (F) Slow cycle cells demonstrated red fluorescence under a fluorescence microscope. (G) Cells observed under a light microscope mixed together with fluorescence microscope, the arrow points to a slow cycle cell which is smaller than quick cycle cells. (H) FCM analysis indicated a slow cycle cell proportion of $1.4 \%$. SP, side population.

increased compared to quick cycle cells $(1.86 \pm 1.12 \%)(\mathrm{t}=5.462$, $\mathrm{p}<0.01$ ) (Fig. 3B).

The expressions of OCT3, SOX2, TCL1, AKT1 protein/mRNA are elevated in SP or slow cycle cells. Western blotting showed that the expressions of OCT3 and SOX2 protein were increased $>2$-fold in SP cells compared to MP cells, and the expressions of TCL1 and AKT1 in SP cells were also elevated. The expression of OCT3 protein in slow cycle cells was $>2$-fold the expression observed in quick cycle cells. The expressions of SOX2, TCL1 and AKT1 were statistically
A

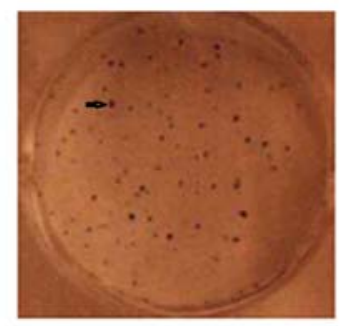

SP

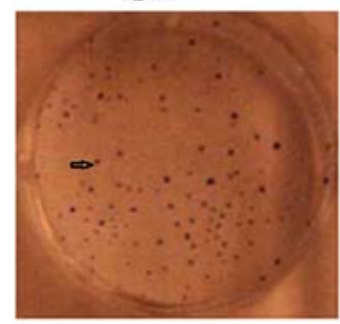

Slow

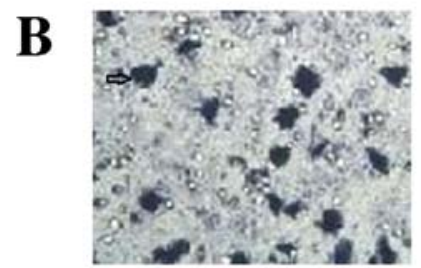

SP

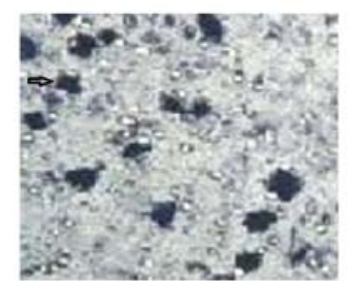

Slow

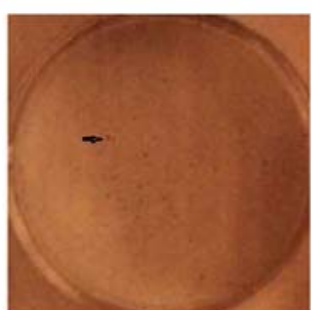

MP

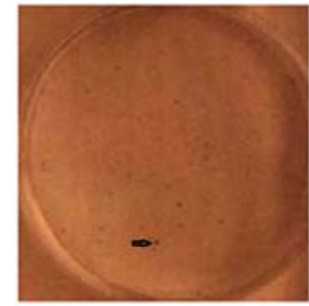

Quick

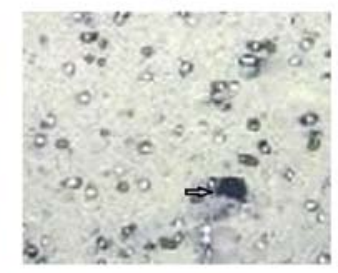

MP

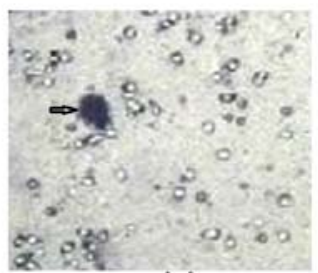

Quick

Figure 3. The ability of clone formation and the invasion of SP cells and slow cycle cells are strengthened. (A) More clone formation is observed for SP cells than MP cells and for slow cycle cells than quick cycle cells (B) Transwell chamber assay indicated that the invasion rate of SP cells increased compared to MP cells and the invasion ability of slow cycle cells was strengthened compared to quick cycle cells. SP, side population.

significantly elevated in slow cycle cells compared to quick cycle cells $(\mathrm{p}<0.05)$ (Fig. 4A). mRNA levels were determined by real-time RT-PCR and the results showed that mRNA levels of OCT3, SOX2, TCL1, AKT1 in SP/slow cycle cells were statistically significantly elevated compared to MP/quick cycle cells $(\mathrm{p}<0.05)$ (Fig. 4B).

OCT3-siRNA downregulates the expression of SOX2, TCL1 and AKT1. After transfection of OE33 SP cells or slow cycle cells with OCT3-siRNA, the expression of OCT3 was statistically significantly decreased compared to control groups, including ConA, ConB or ConN ( $\mathrm{p}<0.01)$. Furthermore, downregulation of OCT3 expression by siRNA reduced the expression of SOX2, TCL1 and AKT1 protein or mRNA statistically significantly compared to control groups $(\mathrm{p}<0.01)$ (Fig. 5). 

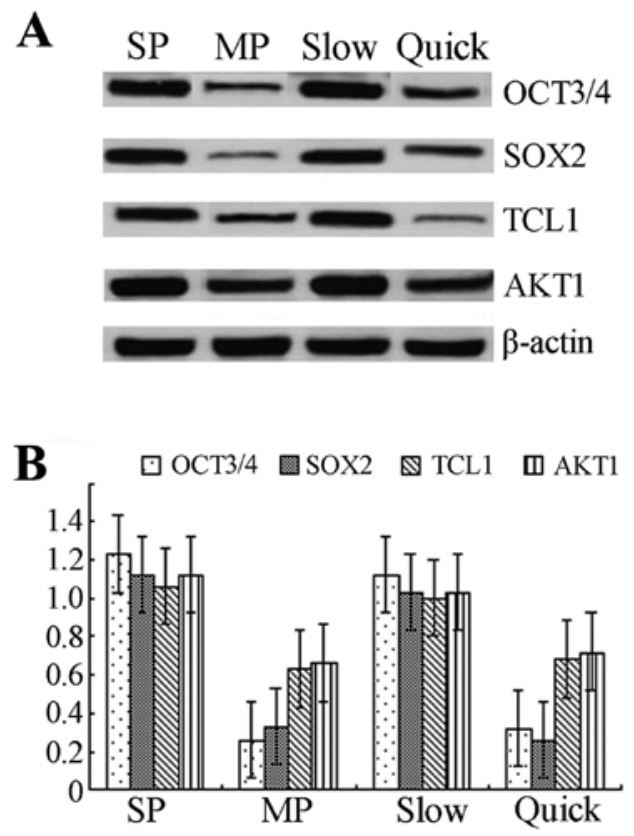

Figure 4. The expressions of OCT3, SOX2, TCL1, AKT1 protein/mRNA are elevated in SP and slow cycle cells, respectively. (A) Results of western blot analysis. (B) Real-time PCR results. OCT3, octamer transcription factor-3; $\mathrm{SP}$, side population.
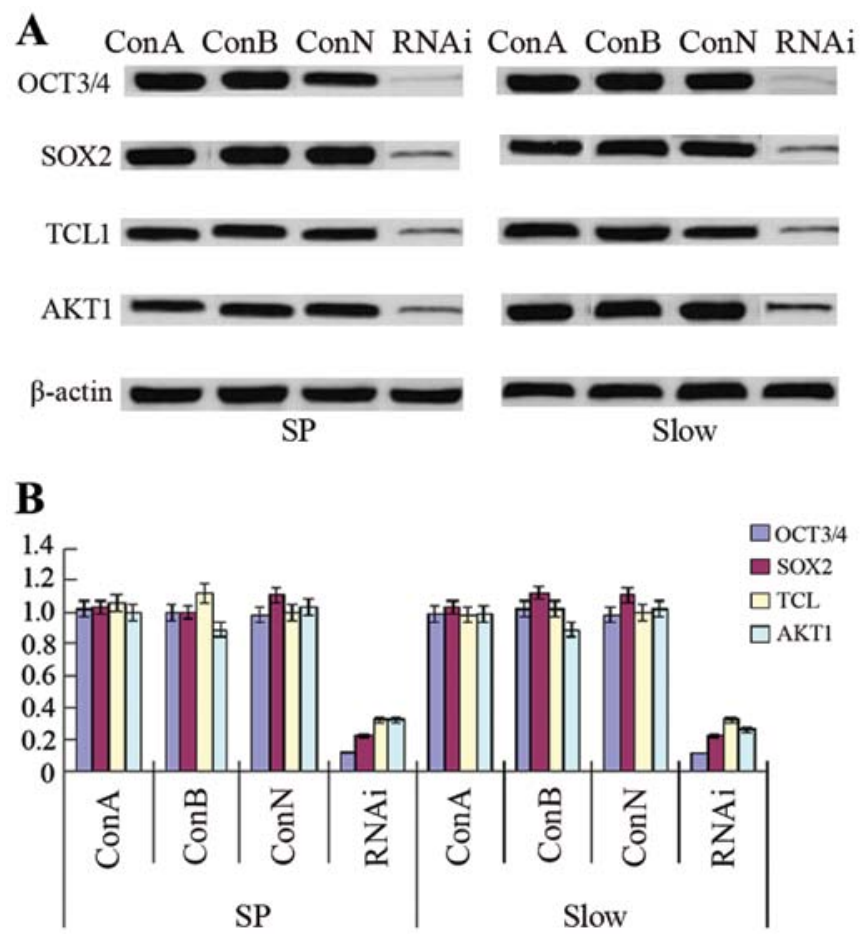

Figure 5. OCT3-siRNA downregulates the expressions of SOX2, TCL1 and AKT1. (A) Western blot analysis indicating the inhibition of SOX2, TCL1 and AKT1 protein by OCT3-siRNA. (B) Real-time PCR demonstrated that OCT3-siRNA downregulated SOX2-, TCL1-, AKT1-mRNA levels. ConB, blank control group; ConA, void vector group; $\mathrm{ConN}$, negative transfection group. OCT3, octamer transcription factor-3.

Downregulation of OCT3 expression by siRNA inhibits the ability of clone formation and invasion. The plate clone formation test showed that the number of clones formed by SP
A
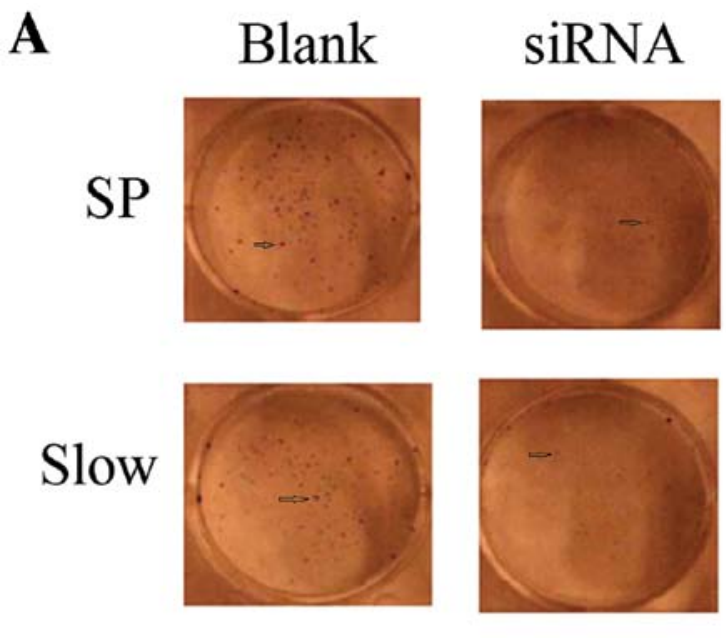

B
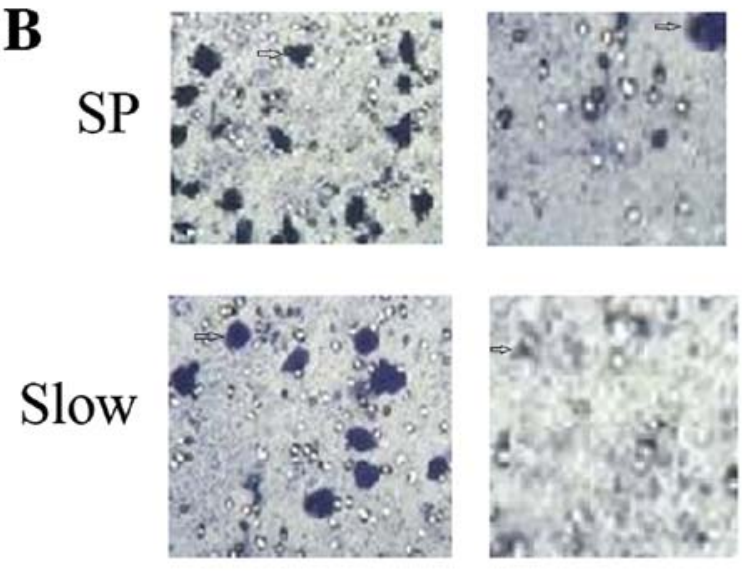

Figure 6. Downregulation of OCT3 expression by siRNA inhibits the ability of clone formation and invasion. (A) The plate clone formation test indicated that the number of clones formed by SP or slow cycle cells was reduced by OCT3-siRNA. (B) The Transwell chamber assay indicated a reduced number of Transwelled cells for SP or slow cycle cells after inhibition of OCT3 by siRNA. OCT3, octamer transcription factor-3; SP, side population.

or slow cycle cells is reduced by OCT3-siRNA. The invasion ability determined by Transwell chamber assay indicated a reduced number of Transwelled cells for SP or slow cycle cells after inhibition of OCT3 by siRNA (Fig. 6).

OE33 cell transfection with OCT3-siRNA reduces the number of SP cells and slow cycle cells. In order to explore the effects of OCT3-siRNA on tumor stem-like cells in OE33 cells, OE33 cells were transfected with siRNA. After inhibition of OCT3, Hoechst 33342 dyeing showed statistically significantly fewer SP cells being isolated compared to the control with no addition of OCT3-siRNA $(0.34 \pm 0.08$ vs. $1.2 \pm 0.56 \%$, $\mathrm{p}<0.05)$. Moreover, statistically significantly fewer slow cycle cells were detected by Dil dyeing $(0.36 \pm 0.06$ vs. $1.4 \pm 0.68 \%$, p<0.05) (Fig. 7).

\section{Discussion}

As a member of the POU transcription factor family, OCT3 is involved in the self-renewal of embryonic stem cells and primordial germ cells and is considered a marker for the pluripotency of stem cells (9). The expression of OCT3 in differentiated or mature tissue is very low, or even non-existent $(10,11)$. SOX2, 
A
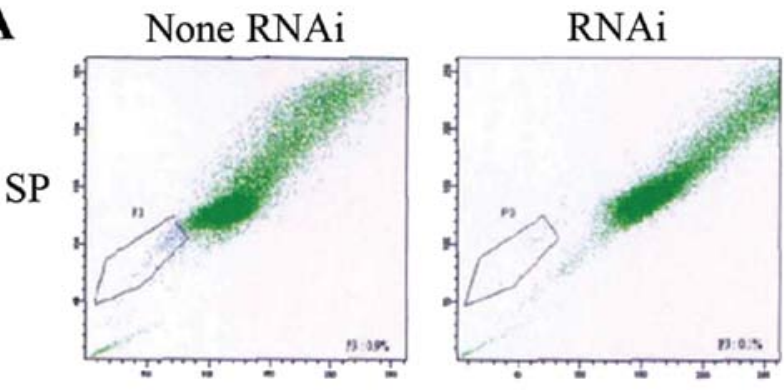

Hoechst

B
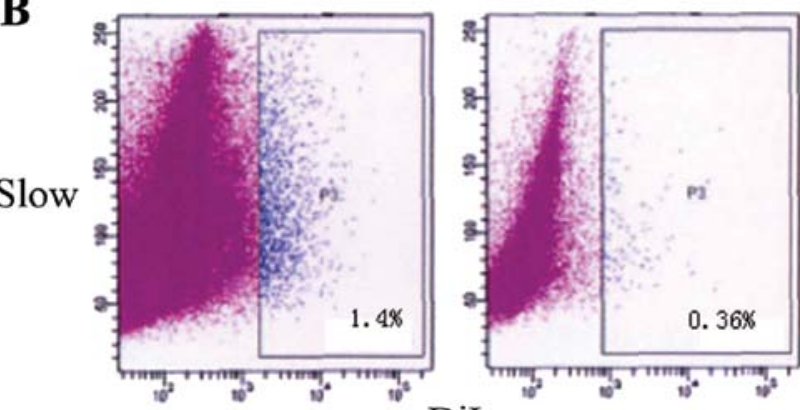

DiI

Figure 7. OCT3-siRNA reduces the number of SP cells and slow cycle cells. (A) Hoechst 33342 dyeing showed fewer SP cells being isolated after inhibition with OCT3-siRNA compared to a control without OCT3-siRNA. (B) After inhibition of OCT3A, a reduced number of slow cycle cells was detected by DiI dyeing. OCT3, octamer transcription factor-3; SP, side population.

as a member of the SOX (SRY-related HMG box) family (12) plays a critical role in the regulation of the development of embryonic stem cells, maintaining pluripotency of stem cells and deciding cell fate $(13,14)$. OCT3 and SOX2 combine together forming a complex (OCT3/SOX2). OCT3 and SOX2 are not only expressed in embryonic stem cells and germ cells but also in some tumor cells as, for example, in breast cancer $(15,16)$, germinoma $(17,18)$, pancreatic $(19,20)$, liver (21), bladder (22), lung cancer (23) and renal medullary carcinoma (24). Furthermore, OCT3 expression is observed in human breast stem cells, pancreatic stem cells, liver stem cells. It is believed that OCT3-positive tumor cells may be derived from OCT3-positive somatic stem cells (21). The expression of OCT3 in BE tissue was found to be elevated compared to normal esophagus tissue, but decreased compared to EAC tissue. We hypothesized that there were a few stem-like cells in BE tissue that were stimulated by some risk factors and then transformed into EAC.

The TCL1 oncogene located at 14q32.1 is involved in the development of human mature T-cell leukemia. It was found as one of the downstream candidate genes of OCT3 and played an important role in early mouse embryos and ES cells (25). It has been shown that TCL1 enhances the kinase activity of AKT1 (26). AKT1 is one of the key kinases enhancing cell proliferation and inhibiting apoptosis. It has also been shown that the activation of AKT1 is sufficient to maintain the undifferentiated state of mouse ES cells (27) and that the OCT3-TCL1-AKT1 pathway plays an important role in early mouse embryos and ES cells (28). In the present study, we also measured the expression of TCL1 and AKT1 in BE or EAC tissue. Notably, we found that TAL1 or AKT1 were also

elevated in BE or EAC tissue compared to normal esophagus tissue. Based on this observation, we hypothesized that the OCT3/SOX2-TCL1-AKT1 pathway plays an important role in the transformation of BE to EAC.

To date, tumor stem cells have been isolated from several different types of cancer, including leukemia $(29,30)$, brain neoplasms $(31,32)$, breast (33), prostate cancer (34), hepatocellular carcinoma (35), colon cancer (36), head and neck squamous cell carcinoma (37). We isolated SP and slow cycle cells having stem cell characteristics using Hoechst 33342 and Dil dye, respectively. Hoechst 33342 is a nuclei fluorescent dye which is pumped by stem cells. Therefore, the stem cells may not be dyed by Hoechst 33342 but are inhibited by a blocking agent (verapamil). Due to this property, SP cells may be isolated using flow cytometry $(38,39)$. SP cells were isolated from neuroblastoma, breast, lung cancer, spongioblastoma (40) and ovarian cancer cell lines (41). SP cells have the same characteristics as stem cells including self-renewal and multi-direction differentiation. The clone formation test was an effective method to detect proliferation of single cells, and the Transwell test was used to check cell metastasis. In the present study, $\sim 1.2 \%$ of cells isolated were SP cells and the ability of clone formation and metastasis of SP cells were increased compared to MP cells.

Another way to separate stem cells involves the mark detaining test which is based on the long cell cycle of stem cells (42). Since stem cells are normally in stationary phase, the marker is detained after a long time in culture and can be detected. However, the marker is diminished with fast dividing and cannot be detected. The cells detected this way are called slow cycle cells and exhibit the characteristics of stem cells. In the past, bromodeoxyuridine (BrdU) was used. A new cell membrane marker, Dil, has recently found widespread application. DiI is a type of lipophilic membrane marker that sends out fluorescence when integrated in the membrane. Its beneficial properties include a higher labeling efficiency, shorter labeling time and less cytotoxicity (43). To date, slow cycle cells have been detected in tumors of, for example, intestine (44), breast (45), skin (46) and cornea (47). In the present study, $\sim 1.4 \pm 0.26 \%$ of cells separated from OE33 cells were considered to be slow cycle cells. Slow cycle cells are smaller than quick cycle cells and have a strengthened ability of clone formation and invasion.

In the present study, the regulatory role of downregulation of OCT3 by siRNA was elucidated. RNAi is an effective way to silence post transcriptional genes and is extensively used to inhibit specific gene expression $(48,49)$. OE33 cells were transfected with OCT3-siRNA to silence OCT3 expression. Downregulation of OCT3 expression by siRNA inhibited the clone formation and invasion ability of OE33 cells. It has been shown that inhibition of OCT3 reduces tumor malignancy. Recent studies showed that somatic stem cells with high expression levels of OCT3 are the origin of tumorigenesis $(21,50,51)$, and knocking out the OCT4 gene in mice causes embryo death during the prophase of embryo development (52) and causes embryo stem cell differentiation to the endoblast directly (53). This study demonstrated that the downregulation of OCT3 in OE33 cells decreased the formation of SP and slow cycle cells. Western blotting and real-time PCR detection showed that inhibition of OCT3 reduced the expression of SOX2, TCL1 
and AKT1. Therefore, it is our hypothesis that downregulation of OCT3 may inhibit the carcinogenesis of EAC by reducing the activity of SOX2 and blocking the TCL1/AKT1 pathway.

In conclusion, OCT 3 and SOX2 are markers of tumor stem cells which are highly expressed in BE tissue compared to normal esophagus tissue but their expression is decreased compared to EAC tissue. There are a few stem-like cells in OE33 cells which exhibit similar biological behavior to tumor stem cells. Downregulation of OCT3 expression by siRNA inhibited the ability of clone formation and invasion of OE33 cells, and decreased the formation of SP and slow cycle cells. OCT 3 and SOX2 play a critical role in the transformation of $\mathrm{BE}$ to EAC by regulating the formation of tumor stem cells by switching on the TCL1/AKT1 pathway.

\section{Acknowledgements}

The study was supported by the China Postdoctoral Science Foundation (grant no: 201150M1518).

\section{References}

1. Brown LM, Devesa SS and Chow WH: Incidence of adenocarcinoma of the esophagus among white Americans by sex, stage, and age. J Natl Cancer Inst 100: 1184-1187, 2008.

2. Sharma P: Clinical practice. Barrett's esophagus. New Engl J Med 361: 2548-2556, 2009.

3. Tsai RY: A molecular view of stem cell and cancer cell selfrenewal. Int J Biochem Cell Biol 36: 684-694, 2004

4. Kopper L and Hajdú M: Tumor stem cells. Pathol Oncol Res 10: 69-73, 2004.

5. Chew JL, Loh YH, Zhang W, et al: Reciprocal transcriptional regulation of Pou $5 f 1$ and Sox2 via the Oct $4 /$ Sox 2 complex in embryonic stem cells. Mol Cell Biol 25: 6031-6046, 2005.

6. Okumura-Nakanishi S, Saito M, Niwa H and Ishikawa F: Oct-3/4 and Sox 2 regulate $O c t-3 / 4$ gene in embryonic stem cells. J Biol Chem 280: 5307-5317, 2005.

7. Wang X, Sun Y, Xu M, Fang DC, Gao HJ and Xu JT: Oligomicroarray-based primary study of gene expression profile changes in Barrett's esophagus. Journal of Medical Colleges of PLA 23: 251-257, 2008.

8. Rockett JC, Larkin K, Darnton SJ, Morris AG and Matthews HR: Five newly established oesophageal carcinoma cell lines: phenotypic and immunological characterization. Br J Cancer 75 258-263, 1997.

9. Okamoto K, Okazawa H, Okuda A, Sakai M, Muramatsu M and Hamada $\mathrm{H}$ : A novel octamer binding transcription factor is differentially expressed in mouse embryonic cells. Cell 60 461-472, 1990

10. Pesce M and Schöler HR: Oct-4: gatekeeper in the beginnings of mammalian development. Stem Cells 19: 271-278, 2001.

11. Schöler HR: the POU factors in murine development. Trends Genet 7: 323-329, 1991.

12. Weiss MA: Floppy SOX: mutual induced fit in hmg (high-mobility group) box-DNA recognition. Mol Endocrinol 15: 353-362, 2001

13. Wegner M: From head to toes: the multiple facets of Sox proteins. Nucleic Acids Res 27: 1409-1420, 1999.

14. Boiani M and Schöler HR: Regulatory networks in embryoderived pluripotent stem cells. Nat Rev Mol Cell Biol 6: 872-884, 2005.

15. Jin T, Branch DR, Zhang X, et al: Examination of $P O U$ homeobox gene expression in human breast cancer cells. Int J Cancer 81: 104-112, 1999

16. Rodriguez-Pinilla SM, Sarrio D, Moreno-Bueno G, et al: Sox2: a possible driver of the basal-like phenotype in sporadic breast cancer. Mod Pathol 20: 474-481, 2007.

17. Jones TD, Ulbright TM, Eble JN and Cheng L: OCT4: a sensitive and specific biomarker for intratubular germ cell neoplasia of the testis. Clin Cancer Res 10: 8544-8547, 2004.

18. Rijlaarsdam MA, van Herk HA, Gillis AJ, et al: Specific detection of OCT3/4 isoform A/B/B1 expression in solid (germ cell) tumours and cell lines: confirmation of OCT3/4 specificity for germ cell tumours. Br J Cancer 105: 854-863, 2011.
19. Iki K and Pour PM: Expression of Oct4, a stem cell marker, in the hamster pancreatic cancer model. Pancreatology 6: 406-413, 2006.

20. Sanada Y, Yoshida K, Ohara M, Oeda M, Konishi K and Tsutani Y: Histopathologic evaluation of stepwise progression of pancreatic carcinoma with immunohistochemical analysis of gastric epithelial transcription factor SOX2: comparison of expression patterns between invasive components and cancerous or nonneoplastic intraductal components. Pancreas 32: 164-170, 2006.

21. Tai MH, Chang CC, Kiupel M, Webster JD, Olson LK and Trosko JE: Oct4 expression in adult human stem cells: evidence in support of the stem cell theory of carcinogenesis. Carcinogenesis 26: 495-502, 2005.

22. Ben-Porath I, Thomson MW, Carey VJ, et al: An embryonic stem cell-like gene expression signature in poorly differentiated aggressive human tumors. Nat Genet 40: 499-507, 2008.

23. Karoubi G, Gugger M, Schmid R and Dutly A: OCT4 expression in human non-small cell lung cancer: implications for therapeutic intervention. Interact Cardiovasc Thorac Surg 8: 393-397, 2009.

24. Rao P, Tannir NM and Tamboli P: Expression of OCT3/4 in renal medullary carcinoma represents a potential diagnostic pitfall. Am J Surg Pathol 36: 583-588, 2012.

25. Ivanova N, Dobrin R, Lu R, et al: Dissecting self-renewal in stem cells with RNA interference. Nature 442: 533-538, 2006.

26. Pekarsky Y, Koval A, Hallas C, et al: Tcll enhances Akt kinase activity and mediates its nuclear translocation. Proc Natl Acad Sci USA 97: 3028-3033, 2000.

27. Watanabe S, Umehara H, Murayama K, Okabe M, Kimura T and Nakano T: Activation of Akt signaling is sufficient to maintain pluripotency in mouse and primate embryonic stem cells. Oncogene 25: 2697-2707, 2006.

28. Matoba R, Niwa H, Masui S, et al: Dissecting Oct3/4-regulated gene networks in embryonic stem cells by expression profiling. PLoS One 1: e26, 2006.

29. Lapidot T, Sirard C, Vormoor J, et al: A cell initiating human acute myeloid leukaemia after transplantation into SCID mice. Nature 367: 645-648, 1994.

30. Bonnet D and Dick JE: Human acute myeloid leukemia is organized as a hierarchy that originates from a primitive hematopoietic cell. Nat Med 3: 730-737, 1997.

31. Singh SK, Hawkins C, Clarke ID, et al: Identification of human brain tumour initiating cells. Nature 432: 396-401, 2004.

32. Singh SK, Clarke ID, Hide T and Dirks PB: Cancer stem cells in nervous system tumors. Oncogene 23: 7267-7273, 2004.

33. Al-Hajj M, Wicha MS, Benito-Hernandez A, Morrison SJ and Clarke MF: Prospective identification of tumorigenic breast cancer cells. Proc Natl Acad Sci USA 100: 3983-3988, 2003.

34. Collins AT, Berry PA, Hyde C, Stower MJ and Maitland NJ: Prospective identification of tumorigenic prostate cancer stem cells. Cancer Res 65: 10946-10951, 2005.

35. Suetsugu A, Nagaki M, Aoki H, Motohashi T, Kunisada T and Moriwaki H: Characterization of $\mathrm{CD}_{133^{+}}$hepatocellular carcinoma cells as cancer stem/progenitor cells. Biochem Biophys Res Commun 351: 820-824, 2006.

36. O'Brien CA, Pollett A, Gallinger S and Dick JE: A human colon cancer cell capable of initiating tumour growth in immunodeficient mice. Nature 445: 106-110, 2007.

37. Prince ME, Sivanandan R, Kaczorowski A, et al: Identification of a subpopulation of cells with cancer stem cell properties in head and neck squamous cell carcinoma. Proc Natl Acad Sci USA 104: 973-978, 2007.

38. Zhou S, Sehuetz JD, Bunting KD, et al: The ABC transporter Bcrp1/ABCG2 is expressed in a wide variety of stem cells and is a molecular determinant of the side-population phenotype. Nat Med 7: 1028-1034, 2001.

39. Bunting KD: ABC transporters as phenotypic markers and functional regulators of stem cells. Stem Cells 20: 11-20, 2002.

40. Hirschmann-Jax C, Foster AE, Wulf GG, et al: A distinct 'side population' of cells with high drug efflux capacity in human tumor cells. Proc Natl Acad Sci USA 101: 14228-14233, 2004.

41. Szotek PP, Pieretti-Vanmarcke R, Masiakos PT, et al: Ovarian cancer side population defines cells with stem cell-like characteristics and mullerian inhibiting substance responsiveness. Proc Natl Acad Sci USA 103: 11154-11159, 2006.

42. Zhang J, Niu C, Ye L, et al: Identification of the haematopoietic stem cells niche and control of the niche size. Nature 425: 836-841, 2003.

43. Li N, Yang H, Lu L, Duan C, Zhao C and Zhao H: Comparison of the labeling efficiency of BrdU, DiI and FISH labeling techniques in bone marrow stromal cells. Brain Res 1215: 11-19, 2008. 
44. Potten CS, Owen G and Booth D: Intestinal stem cells protect their genome by selective segregation of template DNA strands. J Cell Sci 115: 2381-2388, 2002.

45. Smith GH: Label-retaining epithelial cells in mouse mammary gland divide asymmetrically and retain their template DNA strands. Development 132: 681-687, 2005

46. Taylor G, Lehrer MS, Jensen PJ, Sun TT and Lavker RM: Involvement of follicular stem cells in forming not only the follicle but also the epidermis. Cell 102: 451-461, 2000.

47. Sun TT and Lavker RM: Corneal epithelial stem cells: past, present, and future. J Investig Dermatol Symp Proc 9: 202-207, 2004.

48. McManus MT and Sharp PA: Gene silencing in mammals by small interfering RNAs. Nat Rev Genet 3: 737-747, 2002.
49. Zhang J and Hua ZC: Targeted gene silencing by small interfering RNA-based knock-down technology. Curr Pharm Biotechnol 5: 1-7, 2004.

50. Monk $\mathrm{M}$ and Holding C: Human embryonic genes re-expressed in cancer cells. Oncogene 20: 8085-8091, 2001.

51. Atlasi Y, Mowla SJ, Ziaee SA and Bahrami AR: OCT-4, an embryonic stem cell marker, is highly expressed in bladder cancer. Int J Cancer 120: 1598-1602, 2007.

52. Nichols J, Zevnik B, Anastassiadis K, et al: Formation of pluripotent stem cells in the mammalian embryo depends on the POU transcription factor Oct4. Cell 95: 379-391, 1998.

53. Niwa H, Miyazaki J and Smith AG: Quantitative expression of Oct-3/4 defines differentiation, dedifferentiation or self-renewal of ES cells. Nat Genet 24: 372-376, 2000. 